OPEN ACCESS

Edited by:

Hua Feng,

Southwest Hospital, Army Medical

University, China

Reviewed by:

Brian McKinnon,

University of Texas Medical Branch at Galveston, United States

Ophir Handzel,

Tel Aviv Sourasky Medical Center,

Israel

*Correspondence:

Hongjun Xiao

xhjent_whxh@hust.edu.cn

${ }^{t}$ These authors have contributed equally to this work

Specialty section:

This article was submitted to Neurodegeneration,

a section of the journal

Frontiers in Neuroscience

Received: 13 September 2021

Accepted: 28 October 2021

Published: 19 November 2021

Citation:

Yu W, Zong S, Du P, Zhou P, Li H,

Wang $E$ and Xiao $H$ (2021) Role of the

Stria Vascularis in the Pathogenesis of Sensorineural Hearing Loss:

A Narrative Review.

Front. Neurosci. 15:774585.

doi: 10.3389/fnins.2021.774585

\section{Role of the Stria Vascularis in the Pathogenesis of Sensorineural Hearing Loss: A Narrative Review}

\author{
Wenting Yu ${ }^{\dagger}$, Shimin Zong ${ }^{\dagger}$, Peiyu Du, Peng Zhou, Hejie Li, Enhao Wang and \\ Hongjun Xiao*
}

Department of Otorhinolaryngology, Union Hospital, Tongji Medical College, Huazhong University of Science and Technology, Wuhan, China

Sensorineural hearing loss is a common sensory impairment in humans caused by abnormalities in the inner ear. The stria vascularis is regarded as a major cochlear structure that can independently degenerate and influence the degree of hearing loss. This review summarizes the current literature on the role of the stria vascularis in the pathogenesis of sensorineural hearing loss resulting from different etiologies, focusing on both molecular events and signaling pathways, and further attempts to explore the underlying mechanisms at the cellular and molecular biological levels. In addition, the deficiencies and limitations of this field are discussed. With the rapid progress in scientific technology, new opportunities are arising to fully understand the role of the stria vascularis in the pathogenesis of sensorineural hearing loss, which, in the future, will hopefully lead to the prevention, early diagnosis, and improved treatment of sensorineural hearing loss.

Keywords: sensorineural hearing loss, stria vascularis, pathogenesis, cell signaling, molecular factors

\section{INTRODUCTION}

Hearing loss is the most common sensory deficit in humans and has a negative influence on 430 million people worldwide, including 34 million children (World Health Organisation, 2021). Most cases of hearing loss are sensorineural and occur due to disease, degeneration, or trauma to the cochlea in the inner ear (Omichi et al., 2019). Common causes of sensorineural hearing loss (SNHL) include hereditary syndromes, non-syndromic hearing loss, presbycusis, and druginduced hearing loss (Kuhn et al., 2011). The possible pathogeneses include vascular disorders, viral infections, endolymphatic hydrops, and rupture of the labyrinthine membrane (Okada et al., 2013). In addition, the spiral ganglion, organ of Corti, or stria vascularis (SV) are regarded as three major cochlear structures that can independently degenerate and influence the degree of hearing loss (Schuknecht and Gacek, 1993; Ohlemiller, 2004).

\footnotetext{
Abbreviations: $\mathrm{AAV}$, adeno-associated virus; $\mathrm{ABR}$, auditory brainstem response; $\mathrm{ARHL}$, age-related hearing loss; $\mathrm{BLB}$, blood-labyrinth barrier; CaCC, calcium-activated chloride channel; CMV, cytomegalovirus; COX1, cytochrome C oxidase I; DPOAE, distortion product otoacoustic emission; dRTA, distal renal tubular acidosis; EP, endocochlear potential; ESRP1, epithelial splicing regulatory protein 1; ET-1, endothelin-1; HC, hair cell; HHL, hereditary hearing loss; HSV-1, herpes simplex virus type 1; IRS, insulin receptor substrate; LSDs, lysosomal storage diseases; MPS, mucopolysaccharidosis; Neu1, neuraminidase-1; NIHL, noise-induced hearing loss; NKCC, Na-K-2Cl-Cotransporter; NKCC1, Na-K-2Cl-Cotransporter-1; $\mathrm{PVM} / \mathrm{Ms}$, tissue perivascular resident macrophages; SNHL, sensorineural hearing loss; SV, stria vascularis; TEM, transmission electron microscopy; TMEM16A, transmembrane protein 16; TSOD, Tsumura Suzuki Obese Diabetes; T2DM, type 2 diabetes mellitus.
} 
The SV is located in the lateral wall of the cochlea, connected externally with the spiral ligament, and internally with the endolymph. The SV is mainly composed of marginal, intermediate, and basal cells (Hibino et al., 2010; Shi, 2016). The structures of the cochlea and SV are shown in Figure 1.

One of the significant functions of the SV is to generate the endocochlear potential (EP), which is essential for audition. It is believed that EP is generated by the transport of potassium from SV into the endolymph (Salt et al., 1987; Wangemann, 1997) in a process involving ion channels and transporters in the SV. Previous studies have found that Na, K-ATPase, Na-K2Cl-Cotransporter (NKCC), Cl- channels CLCNKA/BSND, and CLCNKB/BSND are located in the basolateral membrane of marginal cells (Lang et al., 2007; Nin et al., 2016), the K + channel KCNQ1/KCNE1 is present in the apical membranes of marginal cells (Hibino et al., 2010), and the inwardly rectifying potassium channels Kir4.1 are expressed in the apical membranes of intermediate cells (Chen and Zhao, 2014). These transporters and ion channels have been shown to be involved in the formation of EP, and inhibition of either transporter or ion channels could reduce $\mathrm{EP}$ (Nin et al., 2008).

Another important function of the SV is to regulate the secretion of the endolymph and maintain cochlear homeostasis (Taukulis et al., 2021; Zhang et al., 2021). Among these, $\mathrm{H}(+)$ -ATPase (ATP6V1B1 and ATPV0A4) and bicarbonate/chloride transporter SLC26A4 (Pendrin) are expressed in the SV, and regulate the secretion of $\mathrm{H}+$ and $\mathrm{HCO} 3-$ in the endolymph to maintain $\mathrm{pH}$ homeostasis (Mittal et al., 2017); similarly, the $\mathrm{Ca}(2+)$-ATPase and $\mathrm{Ca}(2+)$ channels expressed in the $\mathrm{SV}$ jointly maintain $\mathrm{Ca}(2+)$ homeostasis in the endolymph (Nin et al., 2016).

\section{METHODS}

A preliminary literature search up to April 2021 was performed using PubMed, using the retrieval formula "(sensorineur ${ }^{\star}[$ Title/Abstract]) AND (hearing[Title/Abstract]) AND (stria vascularis[Title/Abstract])". The obtained papers were classified by etiology according to the title and abstract. Next, the term "stria vascularis" was combined with the following key-words for further search: hereditary hearing loss, druginduced hearing loss, age-related hearing loss, noise-induced hearing loss, autoimmune inner ear disease, and systemic disease. Subsequently, irrelevant articles were eliminated and the remaining articles were examined and elaborated on. In addition, the reference lists of the included articles were manually searched for further applicable sources.

\section{HEREDITARY HEARING LOSS}

The SV plays an important role in HHL pathogenesis. Several researchers have previously summarized the histopathologic findings associated with these genetic mutations, and atrophy or fibrosis of the SV has been observed in many cases, often caused by mutations in GJB2, COCH, and MYH9, as well as by Usher syndrome, and Alport syndrome (Bommakanti et al., 2019; Nicolson, 2021). Syndromic and non-syndromic hereditary hearing loss are the two main forms of hereditary hearing loss (HHL) (Egilmez and Kalcioglu, 2016). Table 1 lists the pathological changes and underlying mechanisms of SV in some previously published cases of syndromic hearing loss.

Mutations in the potassium channel subunit KCNQ1 cause Jervell and Lange-Nielsen syndrome, while potassium channels in the SV play an important role in maintaining EP (Tranebjaerg et al., 1999). Researchers injected a modified Adeno-associated virus (AAV) construct carrying the Kcnq1 expression box into the endolymph of Kcnq1(-/-) mice, and found that Kcnq1 expression was restored in marginal cells of the SV; EP subsequently returned to normal, and hair cell degeneration was corrected. This was therefore validated as a successful gene therapy treatment for gene defects affecting the function of the $\mathrm{SV}$, which could be of great significance for the future treatment of HHL related to SV dysfunction (Chang et al., 2015).

Most cases of congenital SNHL are non-syndromic. Rohacek et al. (2017) performed whole exome sequencing in individuals with SNHL and identified pathogenic mutations in epithelial splicing regulatory protein 1 (ESRP1). In the cochleae of Esrp1-/- mouse embryos, the cell types in the lateral wall of the cochlear epithelium are altered, resulting in an increase in the number Reissner's membrane-related cells at the expense of marginal cells. Aberrant splicing of Fgfr2 blocks SV formation because of erroneous ligand usage (Rohacek et al., 2017).

The a4 subunit is a component of the multi-subunit proton pump $(\mathrm{H}+$-ATPase $)$, and mutations in the ATP6V0A4 gene lead to autosomal recessive distal renal tubular acidosis in patients who often show sensorineural hearing impairment. Lorente de Nó et al. studied the inner ear phenotype of Atp6v0a4 knockout mice and observed severe expansion of the scala media, a flattened and thinner SV, and a lack of endocochlear potential, suggestive of defects in SV function. Atp6v0a4-/- mice showed elevated thresholds in auditory brainstem responses. These findings help to understand the role of Atp6v0a4 expression in the ear and may contribute to the development of effective treatments for distal renal tubular acidosis (dRTA)-associated deafness (Lorente-Cánovas et al., 2013).

BDP1 is a member of the TFIIIB complex, which plays a key role in transcription by RNA polymerase III (Girotto et al., 2013). This mitogen-activated protein kinase, MAP3K1, also plays an important role in several cellular processes (Parker et al., 2015), while SCD5 is an endoplasmic reticulum enzyme that plays a crucial role in regulating lipid metabolism (Lu et al., 2020). All of these genes have been reported to be expressed in the SV, while their mutation can cause hearing loss. Further research on the molecular mechanisms underlying deafness associated with these gene mutations is necessary and will provide new opportunities for the diagnosis and treatment of mutation-related hearing loss.

\section{DRUG-INDUCED HEARING LOSS}

Currently, more than 150 drugs are known to be ototoxic and can cause functional impairment and/or cellular degeneration 


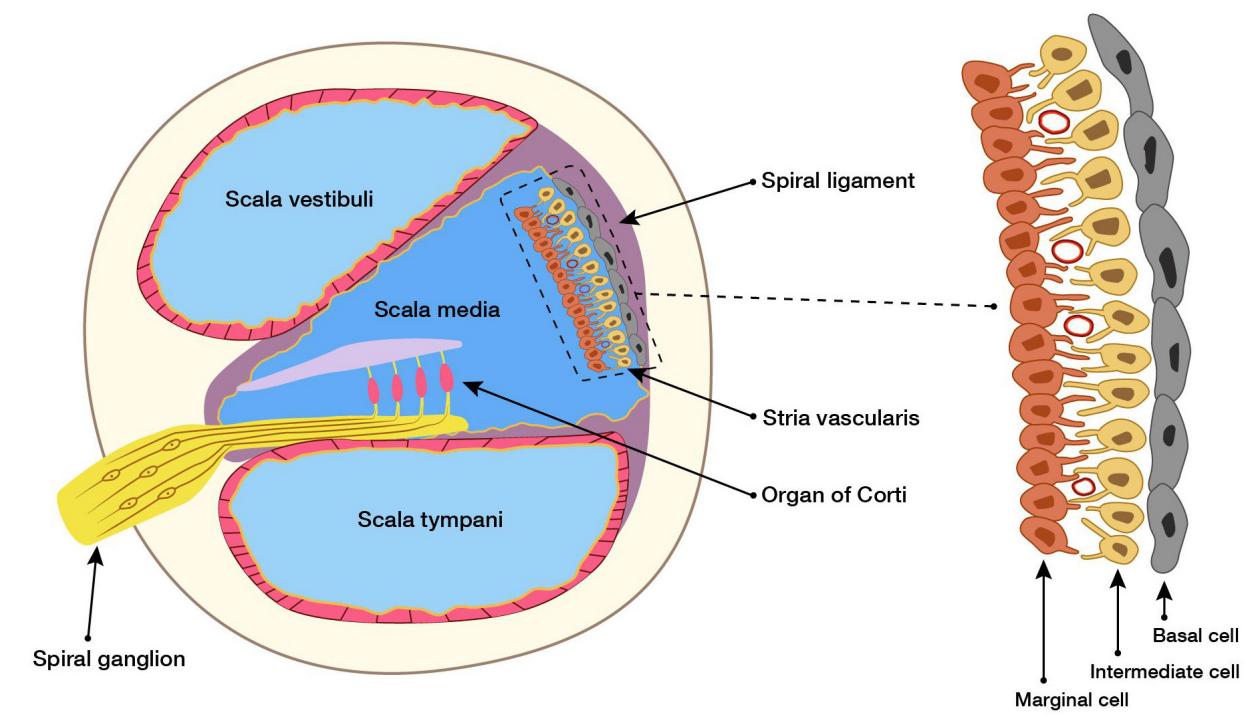

FIGURE 1 | Cross section of the cochlea and structure of SV. Structural and functional damage caused by the SV causes hearing loss, but the mechanism underlying this is unclear. Here, our study reviews the research on the SV in SNHL of different etiologies, and concluded the possible role of the SV in the pathogenesis of SNHL, and aimed to identify new opportunities for the clinical prevention and treatment of SNHL.

of tissues of the inner ear, leading to SNHL (Lanvers-Kaminsky et al., 2017; Guo et al., 2019). The trafficking of ototoxic drugs into the inner ear is generally similar, and all of these drugs must first cross the blood-labyrinth barrier (BLB) of the SV (Salt and Plontke, 2005; Kros and Steyger, 2019); therefore, the SV is considered crucial to their pathogenesis.

Some studies only observed structural abnormalities of SV after treatment with ototoxic drugs, and speculated that the SV was the site of injury to ototoxic drugs. For example, researchers applied drugs such as mitomycin $\mathrm{C}$ or taxol to animals, and found degenerative changes in the cochlea, including vacuolization in the SV and a decrease in the number of fibroblasts. Therefore, researchers speculated that subsequent hearing loss in animals is associated with SV (Atas et al., 2006; Moody et al., 2006).

The pathophysiological mechanisms of drug-induced SV dysfunction are poorly understood, although several studies offer some insights. A significant decline in EP is often observed in patients with drug-induced hearing loss. Recently, damage of the Na, K-ATPase, Na-K-2Cl-Cotransporter-1 (NKCC1), and potassium channel KCNQ1, which are related to EP generation, have received attention (Hellier et al., 2002; Xiong et al., 2011). In a mouse model of SNHL induced by co-administration of aminoglycoside and loop diuretics, researchers observed that both the protein and mRNA expressions of $\alpha 1$ and $\alpha 2$ subtypes of $\mathrm{Na}+/ \mathrm{K}+/$ ATPase and NKCC1 were significantly decreased in the lateral wall, while the expression of KCNQ1 remained unchanged (Salt and Plontke, 2005). These observations provide insight into the detailed mechanisms of EP modulation following SNHL, and may have crucial implications in exploring the mechanisms and future treatment of aminoglycoside-induced SNHL. Recently, the role of inflammation in drug-induced hearing loss has also gained attention. Zhang et al. (2020) found that cisplatin induced the secretion of IL-1 $\beta$ in SV, suggesting that inflammation is involved in the process of cisplatin-induced SV damage.

At present, the cellular and molecular mechanisms underlying SV injury caused by ototoxic drugs are still unknown, and the pathogenesis of different drugs is not identical. Ion channels in SV are still considered a crucial target for future investigations; inflammation may also be a promising target to prevent and treat drug ototoxicity. However, the detailed mechanisms remain to be investigated.

\section{AGE-RELATED HEARING LOSS}

Historical studies have suggested that age-related hearing loss (ARHL) involves a number of auditory structures and mechanisms (Keithley, 2020), including degeneration of the inner and outer hair cells, reduced function of the SV, and degeneration of the auditory nerve (Bowl and Dawson, 2019). ARHL due to functional impairment of the SV is alternatively called strial presbycusis or metabolic presbycusis (Bazard et al., 2021).

One study investigated the morphological changes in the SV of aged mice using TEM, which revealed that the SV in the aged cochlea was degenerated, with a large number of vacuoles and enlarged intercellular spaces (Fetoni et al., 2011; Lyu et al., 2020). However, it is difficult to observe the damage or degenerative changes in the vascular structure of SV using TEM. Carraro et al. (2016) developed a partial corrosion cast method to further investigate the inner ear vasculature, including the capillary structure of the SV and the blood supply of the strial and spiral ligament vessels. Researchers have observed the $\mathrm{SV}$ in presbycusis mice using the novel partial corrosion cast technique, and found that the strial vessels in the basal turn were significantly abnormal, being either thin or absent; however, the 
TABLE 1 | Pathological changes and underlying mechanisms of the SV in different syndromes.

\begin{tabular}{|c|c|c|c|}
\hline & $\begin{array}{l}\text { Relevant } \\
\text { background }\end{array}$ & $\begin{array}{l}\text { Pathological } \\
\text { changes of SV }\end{array}$ & $\begin{array}{l}\text { Possible underlying } \\
\text { mechanisms }\end{array}$ \\
\hline $\begin{array}{l}\text { Alport } \\
\text { syndrome }\end{array}$ & $\begin{array}{l}\text { Alport syndrome is } \\
\text { a relatively common } \\
\text { heritable basement } \\
\text { membrane } \\
\text { disorder, caused by } \\
\text { mutations in the } \\
\text { genes encoding } \\
\text { collagen alpha3 } \\
\text { (IV), alpha4 (IV), or } \\
\text { alpha5 (IV), and } \\
\text { usually leads to } \\
\text { high-frequency } \\
\text { SNHL }\end{array}$ & $\begin{array}{l}\text { Thickening of the } \\
\text { capillary basement } \\
\text { membrane (Gratton } \\
\text { et al., 2005) }\end{array}$ & $\begin{array}{l}\text { - Increase expression } \\
\text { of a family of matrix } \\
\text { metalloproteinases } \\
\text { (MMPs) caused } \\
\text { degradation of tight } \\
\text { connection in the } \\
\text { SV14 } \\
\text { - Pericyte } \\
\text { abnormalities (Dufek } \\
\text { et al., 2020) } \\
\text { - Endothelin-1 (ET-1) } \\
\text { mediated activation of } \\
\text { endothelin A receptors } \\
\text { on marginal cells } \\
\text { results in thickening of } \\
\text { the strial capillary } \\
\text { basement membranes } \\
\text { (Meehan et al., 2016) }\end{array}$ \\
\hline $\begin{array}{l}\text { Norrie } \\
\text { disease }\end{array}$ & $\begin{array}{l}\text { An } X \text {-linked } \\
\text { recessive genetic } \\
\text { syndrome. The } \\
\text { knockout mice } \\
\text { showed } \\
\text { progressive hearing } \\
\text { loss across all } \\
\text { frequencies. }\end{array}$ & $\begin{array}{l}\text { Significantly } \\
\text { enlarged vessels in } \\
\text { the SV, particularly } \\
\text { in the apex of the } \\
\text { cochlea, and loss } \\
\text { of marginal cells. In } \\
\text { severe cases, the } \\
\text { SV was almost } \\
\text { completely } \\
\text { degenerated (Rehm } \\
\text { et al., 2002) }\end{array}$ & $\begin{array}{l}\text { - Norrin protein } \\
\text { activates canonical } \\
\text { Wnt signaling by } \\
\text { binding to receptor of } \\
\text { Frizzled-4 and this } \\
\text { signaling system is } \\
\text { required for vascular } \\
\text { survival in the SV (Ye } \\
\text { et al., 2011) }\end{array}$ \\
\hline $\begin{array}{l}\text { Lysosomal } \\
\text { storage } \\
\text { diseases }\end{array}$ & $\begin{array}{l}\text { Neuraminidase-1 } \\
\text { (Neu1) deficiency is } \\
\text { associated with } \\
\text { lysosomal storage } \\
\text { diseases (LSDs). } \\
\text { Hearing loss in } \\
\text { Neu1-/- mice } \\
\text { involves both } \\
\text { conductive and } \\
\text { sensorineural } \\
\text { components. }\end{array}$ & $\begin{array}{l}\text { Marginal cells of the } \\
\text { SV in Neu1-/- } \\
\text { cochleae, including } \\
\text { invaginations, } \\
\text { cavities, and } \\
\text { extensive apical } \\
\text { vacuolization in } \\
\text { marginal cells (Guo } \\
\text { et al., 2005; Wu } \\
\text { et al., 2010) }\end{array}$ & \\
\hline \multirow[t]{3}{*}{$\begin{array}{l}\text { Pendred } \\
\text { syndrome }\end{array}$} & \multirow[t]{3}{*}{$\begin{array}{l}\text { Pendred syndrome } \\
\text { is caused by } \\
\text { mutations of } \\
\text { SLC26A4 and } \\
\text { characterized by } \\
\text { deafness with } \\
\text { enlargement of } \\
\text { aqueduct and } \\
\text { goiter }\end{array}$} & \multirow[t]{3}{*}{$\begin{array}{l}\text { SV is significantly } \\
\text { enlarged and can } \\
\text { be visualized } \\
\text { through the } \\
\text { pigmentation of the } \\
\text { intermediate cells } \\
\text { (Xue et al., 2021) }\end{array}$} & $\begin{array}{l}\text { - Upregulation of } \\
\text { Bhmt gene caused a } \\
\text { disruption of nutrient } \\
\text { homeostasis in the } \\
\text { endolymph21 } \\
\text { - Reduction of Kcnj10 } \\
\text { protein expression } \\
\text { under free radical } \\
\text { stress in SV (Singh and } \\
\text { Wangemann, 2008) }\end{array}$ \\
\hline & & & $\begin{array}{l}\text { - Macrophage } \\
\text { invasion contributes to } \\
\text { tissue degeneration in } \\
\text { SV (Jabba et al., 2006) }\end{array}$ \\
\hline & & & $\begin{array}{l}\text { - Pendrin dysfunction } \\
\text { leads to a loss of } \\
\text { KCNJ10 protein } \\
\text { expression and a loss } \\
\text { of EP (Ahmed jan } \\
\text { et al., 2021) }\end{array}$ \\
\hline
\end{tabular}

TABLE 1 | (Continued)

\begin{tabular}{|c|c|c|c|}
\hline & $\begin{array}{l}\text { Relevant } \\
\text { background }\end{array}$ & $\begin{array}{l}\text { Pathological } \\
\text { changes of SV }\end{array}$ & $\begin{array}{l}\text { Possible underlying } \\
\text { mechanisms }\end{array}$ \\
\hline $\begin{array}{l}\text { Waardenburg } \\
\text { syndrome }\end{array}$ & $\begin{array}{l}\text { Waardenburg } \\
\text { syndrome (WS) is } \\
\text { an autosomal } \\
\text { dominant } \\
\text { inherited disease } \\
\text { and caused by } \\
\text { loss of } \\
\text { pigmentary cells } \\
\text { in SV of the } \\
\text { cochlea, eyes, } \\
\text { skin, and hair }\end{array}$ & $\begin{array}{l}\text { Loss of pigmentary } \\
\text { cells in SV and } \\
\text { absence of EP } \\
\text { (Wangemann et al., } \\
\text { 2004) }\end{array}$ & $\begin{array}{l}\text { - Mutations in the } \\
\text { KIT gene interrupt the } \\
\text { development of } \\
\text { melanocytes in } \\
\text { cochlear, causing SV } \\
\text { malformations and } \\
\text { dysfunction and } \\
\text { ultimately leading to } \\
\text { hearing loss (Ni et al., } \\
\text { 2013) } \\
\text { - Lacking of } \\
\text { interaction between } \\
\text { endothelin } 3 \text { and its } \\
\text { receptor resulted in } \\
\text { abnormal } \\
\text { pigmentation and } \\
\text { hearing loss in WS4 } \\
\text { mice (Matsushima } \\
\text { et al., 2002) }\end{array}$ \\
\hline
\end{tabular}

spiral ligament vessels were normal, which suggests that early pathology started at the level of the SV.

Several mechanisms underlying SV dysfunction in ARHL have been described, including mitochondrial dysfunction, ion transport channel damage, oxidative stress, and inflammation. Lyu et al. observed damaged mitochondria with disorganized dysmorphic cristae and decreased cytochrome $\mathrm{C}$ oxidase I (COX1) levels in aged SV, indicating mitochondrial morphological damage and dysfunction (Xiong et al., 2011). Spicer considered that oxidative damage to mitochondria within strial marginal cells causes reduced ATP production, which in turn reduces the $\mathrm{Na}+/ \mathrm{K}+$ ATPase activity, leading to reduced EP and elevated auditory thresholds (Spicer and Schulte, 2005).

Because of their important role in generating and maintaining cochlear potential, $\mathrm{K}+$ channels have been repeatedly studied (Peixoto Pinheiro et al., 2021). However, the transport and secretion of $\mathrm{K}$ in the inner ear is closely related to $\mathrm{Cl}$-. In a guinea pig aging model, Zhou et al. (2019) found that the expression of mRNA and protein levels of transmembrane protein 16 (TMEM16A), a calcium-activated chloride channel (CaCC), in the cochlear SV decreased, while the auditory brainstem response (ABR) thresholds increased. These findings suggest that the downregulation of TMEM16A may be related to ARHL and provide a potential new direction for clinical prevention and treatment of age-related hearing loss (Zhou et al., 2019). In addition, the results from Kamemori et al. (2002) suggested that the pathogenesis of ARHL may be related to expression of the Klotho protein in SV, which modulates ion transport.

Luz and Jiang conducted experiments in SV-k1 cell lines (from SV) and primary marginal cells of the SV, respectively (Jiang et al., 2018; Rivas-Chacón et al., 2021), to explore the oxidative stress mechanism in SV in ARHL. Recently, researchers have identified age-related changes in the morphology and number of macrophages in the human SV, and suggested that further investigations of the role of macrophage-associated inflammation in SV in ARHL are necessary (Noble et al., 2019). 
In the current research, TEM and partial corrosion casting provide a more intuitive understanding of the morphological changes of SV, including some details of vessels in the cochlea. Although there is abundant research on the mechanism of SV dysfunction in ARHL, the exact biological mechanism remains unknown, and thus requires further exploration.

\section{NOISE-INDUCED HEARING LOSS}

Noise-induced hearing loss (NIHL) is one of the most common types of SNHL, affecting more than 600 million people worldwide (Le et al., 2017). A previous study demonstrated that exposure to noise could result in a decrease in vessel diameter, an increase in permeability in vessels of the cochlear SV (Goldwyn and Quirk, 1997), and increased macromolecular transport in the SV (Suzuki et al., 2002). However, the underlying mechanism remains unclear.

Abnormal cochlear microcirculation has long been considered a crucial cause of noise-induced hearing loss (Shi, 2011). Normally, healthy cochlear microcirculation supplies blood to the inner ear, removes metabolites, and maintains cochlear homeostasis (Wangemann, 2002). Shin et al. (2019) observed that after exposure to noise, abnormal cochlear microcirculation led to decreased vascular diameter in SV and cochlear ischemia, and increased the expression of catalase, IL- $1 \beta$, IL- 6 , and TNF- $\alpha$ in the damaged cochlea. Their findings suggested that cochlear microcirculation is involved in SV damage in NIHL and is associated with oxidative stress and inflammation.

It has previously been shown that $\mathrm{NO}$-derived free radicals in the SV participate in the pathophysiology of NIHL (Chen et al., 2005; Han et al., 2018). Shi et al. explored the apoptotic processes in the SV induced by noise and observed an increase in the production of both nitric oxide and ROS in the SV. Their results provided evidence for a noise-NO-ROS-DNA damage linkage, and indicate that this process leads to marginal cell pathology, inducing blood vessel wall damage and dysfunction of cochlear microcirculation (Shi and Nuttall, 2003).

The role of inflammation in NIHL has also been investigated. Adhesion molecules mediate the adhesion and transmigration of leukocytes, and researchers have found that noise activates the expression of adhesion molecules in the SV to induce hearing loss, leading to speculation that inflammation might be one of the mechanisms by which noise impairs SV function. In addition, Mizushima et al. (2017) observed a significant increase in cells expressing the macrophage-specific protein F4/80 in mouse SV after exposure to noise. They subsequently injected mice with clodronate liposomes to induce apoptosis in macrophages and monocytes, and found that clodronate-treated mice exhibited significantly fewer F4/80-positive cells in the SV and reduced ABR threshold shifts after noise exposure compared to untreated mice. However, IL-1 $\beta$ inhibition did not reverse cochlear damage. These findings suggest a functional link between macrophages and NIHL progression, and indicate that macrophages may be a promising therapeutic target in NIHL (Mizushima et al., 2017).

In addition, there are some other possible mechanisms that could benefit our understanding of the pathology of SV after acoustic trauma, such as abnormal pericytes of SV (Shi, 2009) and regulation of tissue perivascular resident macrophages (PVM/Ms) to BLB integrity (Zhang et al., 2013; Wu et al., 2017).

\section{AUTOIMMUNE INNER EAR DISEASE}

Autoimmune inner ear disease is a rare cause of SNHL (Penêda et al., 2019), and its pathogenesis remains unclear. The SV is generally thought to be an immune site in the inner ear because of the existence of BLB (Das et al., 2019); therefore, many scholars believe that SV injury plays an important role in autoimmune inner ear diseases (Mathews et al., 2003).

Degeneration of SV has been observed in different autoimmune mouse models. Previous studies have reported the destruction of the cochlear BLB and immunoglobulin deposition in SV in $\mathrm{C} 3 \mathrm{H} / \mathrm{lpr}$ autoimmune mice, resulting in shifts in the ABR threshold (Trune et al., 1989; McMenomey et al., 1992; Wong et al., 1992; Lin and Trune, 1997; Trune, 1997). Similarly, immunoglobulin G deposition in the SV was observed in another autoimmune mouse strain $(\mathrm{NZB} / \mathrm{kl})$, and there was a correlation between the degree of hearing loss and the severity of SV lesions (Tago and Yanagita, 1992). Kusakari et al. (1992) have further observed inner ear disorders in MRL/lpr autoimmune mice, including degeneration of intermediate cells, widened intercellular spaces, and immunoglobulin $G$ deposition on the basement membrane of strial blood vessels, as well as in the basal infolding of strial marginal cells. The ABR threshold in MRL/lpr mice was significantly increased (Kusakari et al., 1992). These results suggest that such changes in SV may be the cause of SNHL induced by the immune response.

Ruckenstein et al. conducted a series of studies on MRLFas(lpr) mice, which was proposed as a model of autoimmune inner ear disease. They further observed pathological changes in mouse SV, including hydropic degeneration of the SV, antibody deposition in the SV, and reduction in $\mathrm{EP}$, but no reduction in the in $\mathrm{Na}, \mathrm{K}$-ATPase levels. Therefore, they inferred that the reduction of EP may occur as a result of cellular degeneration within the SV (Ruckenstein and $\mathrm{Hu}$, 1999; Ruckenstein et al., 1999a,b,c). Furthermore, Trune-treated MRL/LPR autoimmune mice treated with prednisolone or aldosterone showed an improvement in hearing threshold stria and morphology (Trune et al., 2000). These results confirmed that the SV plays an important role in autoimmune inner ear diseases and provide ideas for the clinical treatment of hearing loss induced by the immune response.

Most previous studies observed typical pathological changes in SV, such as edema degeneration and immunoglobulin deposition; however, investigation of the mechanism is lacking and further exploration will be needed in the future.

\section{HEARING LOSS DUE TO SYSTEMIC DISEASE}

The association between type 2 diabetes mellitus and hearing loss remains controversial (Spankovich and Yerraguntla, 2019). 
SNHL often occurs in patients with type 2 diabetes mellitus (T2DM) (Helzner and Contrera, 2016), and the related cochlear histopathological findings include microangiopathy, and degeneration of the SV and outer hair cells (Fukushima et al., 2006; Samocha-Bonet et al., 2021); however, the mechanism underlying pathogenesis remains unclear (Akinpelu et al., 2014). Tsuda et al. (2016) observed narrowed capillaries and decreased capillary density in SV in Tsumura Suzuki Obese Diabetes (TSOD) mice, which are regarded as a spontaneous type 2 diabetes model. Intracellular edema, dilatation of the intercellular spaces in intermediate cells of the SV, and moderate degenerative changes in the marginal cells of the SV are prominent findings in the cochlea of Zucker diabetic fatty rats. ABR recordings have also shown increased hearing thresholds in diabetic animals (Meyer zum Gottesberge et al., 2015). Mice deficient in the insulin receptor substrate (IRS) develop type 2-like diabetes, while Murillo-Cuesta et al. (2012) observed the traits of SV atrophy, including marginal cell degeneration, dilatation, or merging of the capillaries in IRS2-deficient mice, with profound sensorineural deafness. These results suggest that degeneration of the SV plays a significant role in the pathogenesis of SNHL associated with T2DM.

Congenital and acquired hypothyroidism can result in hearing loss (Psaltakos et al., 2013; Tsai et al., 2020), while in the cochlea of animals with hypothyroidism, large intercellular spaces in the SV with degeneration of marginal and intermediate cells, and inner and outer hair cell degeneration are often observed. Laboratory animals showed increased auditory thresholds. These findings support the idea that SV injury is related to SNHL induced by hypothyroidism (Meyerhoff, 1979).

Several researchers have observed the cochlear structures in mice with hyperlipidemia and found profound edema in SV (Gratton and Wright, 1992; Satar et al., 2001). When viewing the inner ear of hamsters with hyperlipidemia using transmission electron microscopy, many protrusions toward the endolymphatic space on the surface of marginal cells of the SV and vascular degeneration of the marginal cells and intermediate cells of the SV were observed. These results indicate that hypercholesterolemia can lead to functional changes in the cochlea and SNHL (Hidaka, 1997).

Systemic diseases such as diabetes, hypertension, and hyperlipidemia can all cause hearing loss. However, current studies have only proven that the SV is the damaged site of the cochlea, while the underlying pathogenesis is still unknown.

\section{HEARING LOSS CAUSED BY OTHER REASONS}

Cytomegalovirus (CMV) infection is one of the most common causes of congenital hearing loss in children (Prosser et al., 2021) and its pathogenesis is poorly understood (Schleiss, 2011). As mentioned above, Carraro et al. (2017) also used this novel partial corrosion cast technique in mice with CMV infection to explore possible vascular involvement associated with hearing loss (Keithley, 2020). Researchers have observed a significant reduction in vessel diameter in the capillaries of the stria, suggesting that the first affected structures were the strial vessels. Subsequently, Carraro et al. (2017) further investigated mice in which the cerebral cortex was inoculated with CMV and found that after the virus migrated to the inner ear, most damage was found in the SV at the cochlear apex, including vascular degeneration, loss of capillary network, narrowing of the capillary lumen, while more damaged cochleae show further degeneration toward the base. Some mice infected with CMV completely lost the SV of the cochlear apical vessels. Further, significant elevation in the ABR and distortion product otoacoustic emission (DPOAE) thresholds were observed in CMV-treated mice. It has been suggested that initial auditory threshold loss may be related to strial dysfunction (Carraro et al., 2017). In a similar animal model, Li et al. (2014) observed hyperemia in the SV and spiral ligament, as well as bleeding in the scala vestibule and scala tympani. It could thus be speculated that hearing loss in mice after injection with CMV is associated with permeability changes in the BLB (Li et al., 2014). In another mouse model that simulated human CMV infection, CMV-infected mice were observed to have significant atypical hyperplasia in the cochlear striatum, including downregulation of KCNQ1 protein expression in the striatum, and dysplastic and malformed melanocytes (Melnick and Jaskoll, 2013). In addition, Li et al. (2008) observed viral infection in the SV when establishing an experimental model of CMV-induced hearing loss in newborn mice. These findings reveal a link between SV injury and $\mathrm{CMV}$-induced hearing loss. It could thus be inferred that the SV may be the first cochlear structure to be damaged and may play a significant role in the pathogenesis of CMVinduced hearing loss.

Temporary or permanent SNHL is a sequela of pneumococcal otitis media. Tsuprun et al. (2008) inoculated the middle ear of chinchillas with wild-type Streptococcus pneumoniae, and histological analysis revealed no fluid, inflammatory cells, or bacteria in the middle ear, indicating SNHL. Histopathology of the inner ear revealed edema and injury of the SV, while hair cells and the spiral ganglion seemed to be intact, suggesting that the SV may be the target of otitis media injury, leading to SNHL (Tsuprun et al., 2008).

In Mongolian gerbils with Streptococcus pneumoniae meningitis, Aminpour et al. (2005) observed the complete destruction of SV and moderate to severe hearing loss, and similar results were observed in a rabbit model of pneumococcal meningitis (Rappaport et al., 1999). Stokroos et al. (1998) further observed SV degeneration and rapid hearing loss in guinea pigs infected with herpes simplex virus type 1 (HSV-1) labyrinthitis. These results suggest that SV impairment is associated with hearing loss secondary to bacterial or viral infection, and may have great significance in the early detection and treatment of hearing loss.

Infection with CMV or Streptococcus pneumoniae may lead to SNHL. At present, it could be inferred that SV damage is related to hearing loss. However, the exact mechanism remains to be elucidated. 


\section{DISCUSSION}

The morphological changes and functional impairment of the SV are observed in the pathogenesis of SNHL. Some types of hearing loss share commonalities in their pathogenesis. For example, all ototoxic drugs must cross the BLB to enter the inner ear tissues to exert their cytotoxic effects and induce hearing loss; therefore, extensive vacuolization in the SV has always been observed in related investigations. Moreover, the inner ear has been considered an immune-privileged site because of the presence of BLB (Rivas-Chacón et al., 2021). Autoimmune inner ear disease usually manifests as immunoglobulin $\mathrm{G}$ deposition in the SV. However, it is difficult to find commonalities in the pathogenesis of other types of hearing loss, due to the high heterogeneity; indeed, 200 deafness-related genes were identified (Lang et al., 2007). Hereditary SNHL is associated with complicated and diverse mechanisms. In addition, ARHL is a multifactorial process, each factor has notably different effects between individuals (He et al., 2019), and only a few factors in this process have been researched. Thus, this research represents only "the tip of the iceberg," and it is difficult to formulate a network structure.

The cochlea's small size, fragility, and encasement in the densest bone in the body located deep within the skull make it difficult to dissect and explore (Ren et al., 2019); thus, it

\section{REFERENCES}

Ahmed jan, N., Mui, R. K., and Masood, S. (2021). Waardenburg Syndrome StatPearls. Treasure Island, FL: StatPearls Publishing.

Akinpelu, O. V., Mujica-Mota, M., and Daniel, S. J. (2014). Is type 2 diabetes mellitus associated with alterations in hearing? A systematic review and metaanalysis. Laryngoscope 124, 767-776. doi: 10.1002/lary.24354

Aminpour, S., Tinling, S. P., and Brodie, H. A. (2005). Role of tumor necrosis factor-alpha in sensorineural hearing loss after bacterial meningitis. Otol. Neurotol. 26, 602-609. doi: 10.1097/01.mao.0000178121.28365.0d

Atas, A., Agca, O., Sarac, S., Poyraz, A., and Akyol, M. U. (2006). Investigation of ototoxic effects of Taxol on a mice model. Int. J. Pediatr. Otorhinolaryngol. 70, 779-784. doi: 10.1016/j.ijporl.2005.11.011

Bazard, P., Frisina, R. D., Acosta, A. A., Dasgupta, S., Bauer, M. A., Zhu, X., et al. (2021). Roles of key ion channels and transport proteins in age-related hearing loss. Int. J. Mol. Sci. 22:6158. doi: 10.3390/ijms22116158

Bommakanti, K., Iyer, J. S., and Stankovic, K. M. (2019). Cochlear histopathology in human genetic hearing loss: state of the science and future prospects. Hear. Res. 382:107785. doi: 10.1016/j.heares.2019.107785

Bowl, M. R., and Dawson, S. J. (2019). Age-related hearing loss. Cold Spring Harb. Perspect. Med. 9:a033217. doi: 10.1101/cshperspect.a033217

Carraro, M., Almishaal, A., Hillas, E., Firpo, M., Park, A., and Harrison, R. V. (2017). Cytomegalovirus (CMV) infection causes degeneration of cochlear vasculature and hearing loss in a mouse model. J. Assoc. Res. Otolaryngol. 18, 263-273. doi: 10.1007/s10162-016-0606-4

Carraro, M., Park, A. H., and Harrison, R. V. (2016). Partial corrosion casting to assess cochlear vasculature in mouse models of presbycusis and CMV infection. Hear. Res. 332, 95-103. doi: 10.1016/j.heares.2015.11.010

Chang, Q., Wang, J., Li, Q., Kim, Y., Zhou, B., Wang, Y., et al. (2015). Virally mediated Kcnq1 gene replacement therapy in the immature scala media restores hearing in a mouse model of human Jervell and Lange-Nielsen deafness syndrome. EMBO Mol. Med. 7, 1077-1086. doi: 10.15252/emmm.20140 4929 has not been thoroughly explored in the current literature. With the development of microscopic imaging techniques and improved molecular biology experimental technology, morphological studies have become increasingly available, and have provided us with a new opportunity to perform research on the function of the stria vascularis, for example, investigating the endocochlear potential and ion channels.

Although the current research on the SV in SNHL is still fragmented and unsystematic, we believe that the SV plays an important role in SNHL and look forward to further investigations on the mechanisms underlying of SNHL, which should identify new targets for the prevention and treatment of SNHL.

\section{AUTHOR CONTRIBUTIONS}

WY and SZ wrote the manuscript. All authors contributed to the article and approved the submitted version.

\section{FUNDING}

This work was supported by the National Natural Science Foundation of China (Grant numbers 81771002 and 82071057).

Chen, J., and Zhao, H. B. (2014). The role of an inwardly rectifying $\mathrm{K}(+)$ channel (Kir4.1) in the inner ear and hearing loss. Neuroscience 265, 137-146. doi: 10.1016/j.neuroscience.2014.01.036

Chen, Y. S., Tseng, F. Y., Liu, T. C., Lin-Shiau, S. Y., and Hsu, C. J. (2005). Involvement of nitric oxide generation in noise-induced temporary threshold shift in guinea pigs. Hear. Res. 203, 94-100. doi: 10.1016/j.heares.2004.12.006

Das, S., Bakshi, S. S., and Seepana, R. (2019). Demystifying autoimmune inner ear disease. Eur. Arch. Otorhinolaryngol. 276, 3267-3274. doi: 10.1007/s00405-01905681-5

Dufek, B., Meehan, D. T., Delimont, D., Samuelson, G., Madison, J., Shi, X., et al. (2020). Pericyte abnormalities precede strial capillary basement membrane thickening in Alport mice. Hear. Res. 390:107935. doi: 10.1016/j.heares.2020. 107935

Egilmez, O. K., and Kalcioglu, M. T. (2016). Genetics of nonsyndromic congenital hearing loss. Scientifica 2016:7576064. doi: 10.1155/2016/7576064

Fetoni, A. R., Picciotti, P. M., Paludetti, G., and Troiani, D. (2011). Pathogenesis of presbycusis in animal models: a review. Exp. Gerontol. 46, 413-425. doi: 10.1016/j.exger.2010.12.003

Fukushima, H., Cureoglu, S., Schachern, P. A., Paparella, M. M., Harada, T., and Oktay, M. F. (2006). Effects of type 2 diabetes mellitus on cochlear structure in humans. Arch. Otolaryngol. Head Neck Surg. 132, 934-938. doi: 10.1001/ archotol.132.9.934

Girotto, G., Abdulhadi, K., Buniello, A., Vozzi, D., Licastro, D., d'Eustacchio, A., et al. (2013). Linkage study and exome sequencing identify a BDP1 mutation associated with hereditary hearing loss. PLoS One 8:e80323. doi: 10.1371/ journal.pone.0080323

Goldwyn, B. G., and Quirk, W. S. (1997). Calcium channel blockade reduces noiseinduced vascular permeability in cochlear stria vascularis. Laryngoscope 107, 1112-1116. doi: 10.1097/00005537-199708000-00019

Gratton, M. A., Rao, V. H., Meehan, D. T., Askew, C., and Cosgrove, D. (2005). Matrix metalloproteinase dysregulation in the stria vascularis of mice with Alport syndrome: implications for capillary basement membrane pathology. Am. J. Pathol. 166, 1465-1474. doi: 10.1016/s0002-9440(10)62363-2 
Gratton, M. A., and Wright, C. G. (1992). Alterations of inner ear morphology in experimental hypercholesterolemia. Hear. Res. 61, 97-105. doi: 10.1016/03785955(92)90040-t

Guo, J., Chai, R., Li, H., and Sun, S. (2019). Protection of hair cells from ototoxic drug-induced hearing loss. Adv. Exp. Med. Biol. 1130, 17-36. doi: 10.1007/978981-13-6123-4_2

Guo, Y. K., Xie, D. H., and Yang, X. M. (2005). [Morphological and functional alterations of ear in lysosomal neuraminidase gene deficient mouse]. Zhonghua Er Bi Yan Hou Tou Jing Wai Ke Za Zhi 40, 824-829.

Han, W. J., Shi, X. R., and Nuttall, A. (2018). Distribution and change of peroxynitrite in the guinea pig cochlea following noise exposure. Biomed. Rep. 9, 135-141. doi: 10.3892/br.2018.1107

He, Z. H., Li, M., Zou, S. Y., Liao, F. L., Ding, Y. Y., Su, H. G., et al. (2019). Protection and prevention of age-related hearing loss. Adv. Exp. Med. Biol. 1130, 59-71. doi: 10.1007/978-981-13-6123-4_4

Hellier, W. P., Wagstaff, S. A., O’Leary, S. J., and Shepherd, R. K. (2002). Functional and morphological response of the stria vascularis following a sensorineural hearing loss. Hear. Res. 172, 127-136. doi: 10.1016/s0378-5955(02)00553-1

Helzner, E. P., and Contrera, K. J. (2016). Type 2 diabetes and hearing impairment. Curr. Diab. Rep. 16:3. doi: 10.1007/s11892-015-0696-0

Hibino, H., Nin, F., Tsuzuki, C., and Kurachi, Y. (2010). How is the highly positive endocochlear potential formed? The specific architecture of the stria vascularis and the roles of the ion-transport apparatus. Pflugers. Arch. 459, 521-533. doi: 10.1007/s00424-009-0754-Z

Hidaka, T. (1997). [Scanning and transmission electron microscopic observations of the inner ear of hamsters with hyperlipidemia]. Nihon Jibiinkoka Gakkai Kaiho 100, 900-908. doi: 10.3950/jibiinkoka.100.900

Jabba, S. V., Oelke, A., Singh, R., Maganti, R. J., Fleming, S., Wall, S. M., et al. (2006). Macrophage invasion contributes to degeneration of stria vascularis in Pendred syndrome mouse model. BMC Med. 4:37. doi: 10.1186/1741-7015-4-37

Jiang, H. Y., Yang, Y., Zhang, Y. Y., Xie, Z., Zhao, X. Y., Sun, Y., et al. (2018). The dual role of poly(ADP-ribose) polymerase-1 in modulating parthanatos and autophagy under oxidative stress in rat cochlear marginal cells of the stria vascularis. Redox Biol. 14, 361-370. doi: 10.1016/j.redox.2017.10.002

Kamemori, M., Ohyama, Y., Kurabayashi, M., Takahashi, K., Nagai, R., and Furuya, N. (2002). Expression of Klotho protein in the inner ear. Hear. Res. 171, 103-110. doi: 10.1016/s0378-5955(02)00483-5

Keithley, E. M. (2020). Pathology and mechanisms of cochlear aging. J. Neurosci. Res. 98, 1674-1684. doi: 10.1002/jnr.24439

Kros, C. J., and Steyger, P. S. (2019). Aminoglycoside- and cisplatin-induced ototoxicity: mechanisms and otoprotective strategies. Cold Spring Harb. Perspect. Med. 9:a033548. doi: 10.1101/cshperspect.a033548

Kuhn, M., Heman-Ackah, S. E., Shaikh, J. A., and Roehm, P. C. (2011). Sudden sensorineural hearing loss: a review of diagnosis, treatment, and prognosis. Trends Amplif. 15, 91-105. doi: 10.1177/1084713811408349

Kusakari, C., Hozawa, K., Koike, S., Kyogoku, M., and Takasaka, T. (1992). MRL/MP-lpr/lpr mouse as a model of immune-induced sensorineural hearing loss. Ann. Otol. Rhinol. Laryngol. Suppl. 157, 82-86. doi: 10.1177/ 0003489492101 s1017

Lang, F., Vallon, V., Knipper, M., and Wangemann, P. (2007). Functional significance of channels and transporters expressed in the inner ear and kidney. Am. J. Physiol. Cell Physiol. 293, C1187-C1208. doi: 10.1152/ajpcell.00024.2007

Lanvers-Kaminsky, C., Zehnhoff-Dinnesen, A. A., Parfitt, R., and Ciarimboli, G. (2017). Drug-induced ototoxicity: mechanisms, Pharmacogenetics, and protective strategies. Clin. Pharmacol. Ther. 101, 491-500. doi: 10.1002/cpt.603

Le, T. N., Straatman, L. V., Lea, J., and Westerberg, B. (2017). Current insights in noise-induced hearing loss: a literature review of the underlying mechanism, pathophysiology, asymmetry, and management options. J. Otolaryngol. Head Neck Surg. 46:41. doi: 10.1186/s40463-017-0219-x

Li, L., Kosugi, I., Han, G. P., Kawasaki, H., Arai, Y., Takeshita, T., et al. (2008). Induction of cytomegalovirus-infected labyrinthitis in newborn mice by lipopolysaccharide: a model for hearing loss in congenital CMV infection. Lab. Invest. 88, 722-730. doi: 10.1038/labinvest.2008.39

Li, X., Shi, X., Qiao, Y., Xu, K., Zeng, L., Wang, C., et al. (2014). Observation of permeability of blood-labyrinth barrier during cytomegalovirus-induced hearing loss. Int. J. Pediatr. Otorhinolaryngol. 78, 995-999. doi: 10.1016/j.ijporl. 2014.03.013
Lin, D. W., and Trune, D. R. (1997). Breakdown of stria vascularis blood-labyrinth barrier in C3H/lpr autoimmune disease mice. Otolaryngol. Head Neck Surg. 117, 530-534. doi: 10.1016/s0194-5998(97)70026-3

Lorente-Cánovas, B., Ingham, N., Norgett, E. E., Golder, Z. J., Karet Frankl, F. E., and Steel, K. P. (2013). Mice deficient in H+-ATPase a4 subunit have severe hearing impairment associated with enlarged endolymphatic compartments within the inner ear. Dis. Model Mech. 6, 434-442. doi: 10.1242/dmm.01 0645

Lu, X., Zhang, Y., Chen, L., Wang, Q., Zeng, Z., Dong, C., et al. (2020). Whole exome sequencing identifies SCD5 as a novel causative gene for autosomal dominant nonsyndromic deafness. Eur. J. Med. Genet. 63:103855. doi: 10.1016/ j.ejmg.2020.103855

Lyu, A. R., Kim, T. H., Park, S. J., Shin, S. A., Jeong, S. H., Yu, Y., et al. (2020). Mitochondrial damage and necroptosis in aging cochlea. Int. J. Mol. Sci. 21:2505. doi: 10.3390/ijms21072505

Mathews, J., Rao, S., and Kumar, B. N. (2003). Autoimmune sensorineural hearing loss: is it still a clinical diagnosis? J. Laryngol. Otol. 117, 212-214. doi: 10.1258/ 002221503321192548

Matsushima, Y., Shinkai, Y., Kobayashi, Y., Sakamoto, M., Kunieda, T., and Tachibana, M. (2002). A mouse model of Waardenburg syndrome type 4 with a new spontaneous mutation of the endothelin-B receptor gene. Mamm. Genome 13, 30-35. doi: 10.1007/s00335-001-3038-2

McMenomey, S. O., Russell, N. J., Morton, J. I., and Trune, D. R. (1992). Stria vascularis ultrastructural pathology in the $\mathrm{C} 3 \mathrm{H} / \mathrm{lpr}$ autoimmune strain mouse: a potential mechanism for immune-related hearing loss. Otolaryngol. Head Neck Surg. 106, 288-295. doi: 10.1177/019459989210 600317

Meehan, D. T., Delimont, D., Dufek, B., Zallocchi, M., Phillips, G., Gratton, M. A., et al. (2016). Endothelin-1 mediated induction of extracellular matrix genes in strial marginal cells underlies strial pathology in Alport mice. Hear. Res. 341, 100-108. doi: 10.1016/j.heares.2016.08.003

Melnick, M., and Jaskoll, T. (2013). An in vitro mouse model of congenital cytomegalovirus-induced pathogenesis of the inner ear cochlea. Birth Defects Res. A Clin. Mol. Teratol. 97, 69-78. doi: 10.1002/bdra.23105

Meyer zum Gottesberge, A. M., Massing, T., Sasse, A., Palma, S., and Hansen, S. (2015). Zucker diabetic fatty rats, a model for type 2 diabetes, develop an inner ear dysfunction that can be attenuated by losartan treatment. Cell Tissue Res. 362, 307-315. doi: 10.1007/s00441-015-2215-7

Meyerhoff, W. L. (1979). Hypothyroidism and the ear: electrophysiological, morphological, and chemical considerations. Laryngoscope 89(10 Pt 2 Suppl. 19), 1-25. doi: 10.1002/lary.5540891501

Mittal, R., Aranke, M., Debs, L. H., Nguyen, D., Patel, A. P., Grati, M., et al. (2017). Indispensable Role of Ion Channels and Transporters in the Auditory System. J. Cell. Physiol. 232, 743-758. doi: 10.1002/jcp.25631

Mizushima, Y., Fujimoto, C., Kashio, A., Kondo, K., and Yamasoba, T. (2017). Macrophage recruitment, but not interleukin 1 beta activation, enhances noiseinduced hearing damage. Biochem. Biophys. Res. Commun. 493, 894-900. doi: 10.1016/j.bbrc.2017.09.124

Moody, M. W., Lang, H., Spiess, A. C., Smythe, N., Lambert, P. R., and Schmiedt, R. A. (2006). Topical application of mitomycin C to the middle ear is ototoxic in the gerbil. Otol. Neurotol. 27, 1186-1192. doi: 10.1097/01.mao.0000226306. 43951.c8

Murillo-Cuesta, S., Camarero, G., González-Rodríguez, A., De La Rosa, L. R., Burks, D. J., Avendaño, C., et al. (2012). Insulin receptor substrate 2 (IRS2)deficient mice show sensorineural hearing loss that is delayed by concomitant protein tyrosine phosphatase 1B (PTP1B) loss of function. Mol. Med. 18, 260-269. doi: 10.2119/molmed.2011.00328

Ni, C., Zhang, D., Beyer, L. A., Halsey, K. E., Fukui, H., Raphael, Y., et al. (2013). Hearing dysfunction in heterozygous Mitf(Mi-wh) /+ mice, a model for Waardenburg syndrome type 2 and Tietz syndrome. Pigment Cell Melanoma Res. 26, 78-87. doi: $10.1111 /$ pcmr.12030

Nicolson, T. (2021). Navigating hereditary hearing loss: pathology of the inner ear. Front. Cell Neurosci. 15:660812. doi: 10.3389/fncel.2021.660812

Nin, F., Hibino, H., Doi, K., Suzuki, T., Hisa, Y., and Kurachi, Y. (2008). The endocochlear potential depends on two $\mathrm{K}+$ diffusion potentials and an electrical barrier in the stria vascularis of the inner ear. Proc. Natl. Acad. Sci. U.S.A. 105, 1751-1756. doi: 10.1073/pnas.0711463105 
Nin, F., Yoshida, T., Sawamura, S., Ogata, G., Ota, T., Higuchi, T., et al. (2016). The unique electrical properties in an extracellular fluid of the mammalian cochlea; their functional roles, homeostatic processes, and pathological significance. Pflugers. Arch. 468, 1637-1649. doi: 10.1007/s00424-016-1871-0

Noble, K. V., Liu, T., Matthews, L. J., Schulte, B. A., and Lang, H. (2019). Agerelated changes in immune cells of the human cochlea. Front. Neurol. 10:895. doi: 10.3389/fneur.2019.00895

Ohlemiller, K. K. (2004). Age-related hearing loss: the status of Schuknecht's typology. Curr. Opin. Otolaryngol. Head. Neck. Surg. 12, 439-443. doi: 10.1097/ 01.moo.0000134450.99615.22

Okada, M., Kawaguchi, A. T., Hakuba, N., Hyodo, J., Hato, N., and Gyo, K. (2013). Liposome-encapsulated hemoglobin alleviates hearing loss after transient cochlear ischemia: an experimental study in the gerbil. Neurosci. Lett. 553, 176-180. doi: 10.1016/j.neulet.2013.08.043

Omichi, R., Shibata, S. B., Morton, C. C., and Smith, R. J. H. (2019). Gene therapy for hearing loss. Hum. Mol. Genet. 28, R65-R79. doi: 10.1093/hmg/ddz129

Parker, A., Cross, S. H., Jackson, I. J., Hardisty-Hughes, R., Morse, S., Nicholson, G., et al. (2015). The goya mouse mutant reveals distinct newly identified roles for MAP3K1 in the development and survival of cochlear sensory hair cells. Dis. Model Mech. 8, 1555-1568. doi: 10.1242/dmm.0 23176

Peixoto Pinheiro, B., Vona, B., Löwenheim, H., Rüttiger, L., Knipper, M., and Adel, Y. (2021). Age-related hearing loss pertaining to potassium ion channels in the cochlea and auditory pathway. Pflugers. Arch. 473, 823-840. doi: 10.1007/ s00424-020-02496-w

Penêda, J. F., Lima, N. B., Monteiro, F., Silva, J. V., Gama, R., and Condé, A. (2019). Immune-mediated inner ear disease: diagnostic and therapeutic approaches. Acta Otorrinolaringol. Esp. 70, 97-104. doi: 10.1016/j.otorri.2017.08.008

Prosser, J. D., Holmes, T. W., Seyyedi, M., and Choo, D. I. (2021). Congenital cytomegalovirus (CMV) for the pediatric otolaryngologist. Int. J. Pediatr. Otorhinolaryngol. 148:110809. doi: 10.1016/j.ijporl.2021.110809

Psaltakos, V., Balatsouras, D. G., Sengas, I., Ferekidis, E., Riga, M., and Korres, S. G. (2013). Cochlear dysfunction in patients with acute hypothyroidism. Eur. Arch. Otorhinolaryngol. 270, 2839-2848. doi: 10.1007/s00405-012-2332-9

Rappaport, J. M., Bhatt, S. M., Kimura, R. S., Lauretano, A. M., and Levine, R. A. (1999). Electron microscopic temporal bone histopathology in experimental pneumococcal meningitis. Ann. Otol. Rhinol. Laryngol. 108, 537-547. doi: 10. 1177/000348949910800603

Rehm, H. L., Zhang, D. S., Brown, M. C., Burgess, B., Halpin, C., Berger, W., et al. (2002). Vascular defects and sensorineural deafness in a mouse model of Norrie disease. J. Neurosci. 22, 4286-4292. doi: 10.1523/jneurosci.22-11-04286.2002

Ren, Y., Landegger, L. D., and Stankovic, K. M. (2019). Gene therapy for human sensorineural hearing loss. Front. Cell Neurosci. 13:323. doi: 10.3389/fncel.2019. 00323

Rivas-Chacón, L. D. M., Martínez-Rodríguez, S., Madrid-García, R., Yanes-Díaz, J., Riestra-Ayora, J. I., Sanz-Fernández, R., et al. (2021). Role of oxidative stress in the senescence pattern of auditory cells in age-related hearing loss. Antioxidants 10:1497. doi: 10.3390/antiox10091497

Rohacek, A. M., Bebee, T. W., Tilton, R. K., Radens, C. M., McDermott-Roe, C., Peart, N., et al. (2017). ESRP1 mutations cause hearing loss due to defects in alternative splicing that disrupt cochlear development. Dev. Cell 43, 318.e5331.e5. doi: 10.1016/j.devcel.2017.09.026

Ruckenstein, M. J., and Hu, L. (1999). Antibody deposition in the stria vascularis of the MRL-Fas(lpr) mouse. Hear. Res. 127, 137-142. doi: 10.1016/s0378-5955(98) 00189-0

Ruckenstein, M. J., Keithley, E. M., Bennett, T., Powell, H. C., Baird, S., and Harris, J. P. (1999a). Ultrastructural pathology in the stria vascularis of the MRL-Fasl(lpr) mouse. Hear. Res. 131, 22-28. doi: 10.1016/s0378-5955(99)00 018-0

Ruckenstein, M. J., Milburn, M., and Hu, L. (1999b). Strial dysfunction in the MRLFas mouse. Otolaryngol. Head Neck Surg. 121, 452-456. doi: 10.1016/s01945998(99)70236-6

Ruckenstein, M. J., Sarwar, A., Hu, L., Shami, H., and Marion, T. N. (1999c). Effects of immunosuppression on the development of cochlear disease in the MRL-Fas(lpr) mouse. Laryngoscope 109, 626-630. doi: 10.1097/00005537199904000-00020

Salt, A. N., Melichar, I., and Thalmann, R. (1987). Mechanisms of endocochlear potential generation by stria vascularis. Laryngoscope 97(8 Pt 1), 984-991.
Salt, A. N., and Plontke, S. K. (2005). Local inner-ear drug delivery and pharmacokinetics. Drug Discov. Today 10, 1299-1306. doi: 10.1016/s13596446(05)03574-9

Samocha-Bonet, D., Wu, B., and Ryugo, D. K. (2021). Diabetes mellitus and hearing loss: a review. Ageing Res. Rev. 71:101423. doi: 10.1016/j.arr.2021.10 1423

Satar, B., Ozkaptan, Y., Sürücü, H. S., and Oztürk, H. (2001). Ultrastructural effects of hypercholesterolemia on the cochlea. Otol. Neurotol. 22, 786-789. doi: 10.1097/00129492-200111000-00012

Schleiss, M. R. (2011). Congenital cytomegalovirus infection: molecular mechanisms mediating viral pathogenesis. Infect Disord. Drug Targets 11, 449-465. doi: 10.2174/187152611797636721

Schuknecht, H. F., and Gacek, M. R. (1993). Cochlear pathology in presbycusis. Ann. Otol. Rhinol. Laryngol. 102(1 Pt 2), 1-16. doi: $10.1177 / 00034894931020$ s101

Shi, X. (2009). Cochlear pericyte responses to acoustic trauma and the involvement of hypoxia-inducible factor-1alpha and vascular endothelial growth factor. Am. J. Pathol. 174, 1692-1704. doi: 10.2353/ajpath.2009.080739

Shi, X. (2011). Physiopathology of the cochlear microcirculation. Hear. Res. 282, 10-24. doi: 10.1016/j.heares.2011.08.006

Shi, X. (2016). Pathophysiology of the cochlear intrastrial fluid-blood barrier (review). Hear. Res. 338, 52-63. doi: 10.1016/j.heares.2016.01.010

Shi, X., and Nuttall, A. L. (2003). Upregulated iNOS and oxidative damage to the cochlear stria vascularis due to noise stress. Brain Res. 967, 1-10. doi: 10.1016/s0006-8993(02)04090-8

Shin, S. A., Lyu, A. R., Jeong, S. H., Kim, T. H., Park, M. J., and Park, Y. H. (2019). Acoustic trauma modulates cochlear blood flow and vasoactive factors in a rodent model of noise-induced hearing loss. Int. J. Mol. Sci. 20:5316. doi: 10.3390/ijms20215316

Singh, R., and Wangemann, P. (2008). Free radical stress-mediated loss of Kcnj10 protein expression in stria vascularis contributes to deafness in Pendred syndrome mouse model. Am. J. Physiol. Renal Physiol. 294, F139-F148. doi: 10.1152/ajprenal.00433.2007

Spankovich, C., and Yerraguntla, K. (2019). Evaluation and management of patients with diabetes and hearing loss. Semin. Hear. 40, 308-314. doi: 10.1055/ s-0039-1697644

Spicer, S. S., and Schulte, B. A. (2005). Pathologic changes of presbycusis begin in secondary processes and spread to primary processes of strial marginal cells. Hear. Res. 205, 225-240. doi: 10.1016/j.heares.2005.03.022

Stokroos, R. J., Albers, F. W., and Schirm, J. (1998). The etiology of idiopathic sudden sensorineural hearing loss. Experimental herpes simplex virus infection of the inner ear. Am. J. Otol. 19, 447-452.

Suzuki, M., Yamasoba, T., Ishibashi, T., Miller, J. M., and Kaga, K. (2002). Effect of noise exposure on blood-labyrinth barrier in guinea pigs. Hear. Res. 164, 12-18. doi: 10.1016/s0378-5955(01)00397-5

Tago, C., and Yanagita, N. (1992). Cochlear and renal pathology in the autoimmune strain mouse. Ann. Otol. Rhinol. Laryngol. Suppl. 157, 87-91. doi: 10.1177/ 0003489492101 s 1018

Taukulis, I. A., Olszewski, R. T., Korrapati, S., Fernandez, K. A., Boger, E. T., Fitzgerald, T. S., et al. (2021). Single-cell RNA-seq of cisplatin-treated adult stria vascularis identifies cell type-specific regulatory networks and novel therapeutic gene targets. Front. Mol. Neurosci. 14:718241. doi: 10.3389/fnmol.2021.718241

Tranebjaerg, L., Bathen, J., Tyson, J., and Bitner-Glindzicz, M. (1999). Jervell and Lange-Nielsen syndrome: a Norwegian perspective. Am. J. Med. Genet. 89, $137-146$.

Trune, D. R. (1997). Cochlear immunoglobulin in the C3H/lpr mouse model for autoimmune hearing loss. Otolaryngol. Head Neck Surg. 117, 504-508. doi: 10.1016/s0194-5998(97)70022-6

Trune, D. R., Craven, J. P., Morton, J. I., and Mitchell, C. (1989). Autoimmune disease and cochlear pathology in the $\mathrm{C} 3 \mathrm{H} / \mathrm{lpr}$ strain mouse. Hear. Res. 38, 57-66. doi: 10.1016/0378-5955(89)90128-7

Trune, D. R., Kempton, J. B., and Kessi, M. (2000). Aldosterone (mineralocorticoid) equivalent to prednisolone (glucocorticoid) in reversing hearing loss in MRL/MpJ-Faslpr autoimmune mice. Laryngoscope 110, 1902-1906. doi: 10.1097/00005537-20001100000025

Tsai, Y. T., Chang, I. J., Hsu, C. M., Yang, Y. H., Liu, C. Y., Tsai, M. S., et al. (2020). Association between sudden sensorineural hearing loss and preexisting thyroid 
diseases: a nationwide case-control Study in Taiwan. Int. J. Environ. Res. Public Health 17:834. doi: 10.3390/ijerph17030834

Tsuda, J., Sugahara, K., Hori, T., Kanagawa, E., Takaki, E., Fujimoto, M., et al. (2016). A study of hearing function and histopathologic changes in the cochlea of the type 2 diabetes model Tsumura Suzuki obese diabetes mouse. Acta Otolaryngol. 136, 1097-1106. doi: 10.1080/00016489.2016.1195012

Tsuprun, V., Cureoglu, S., Schachern, P. A., Ferrieri, P., Briles, D. E., Paparella, M. M., et al. (2008). Role of pneumococcal proteins in sensorineural hearing loss due to otitis media. Otol. Neurotol. 29, 1056-1060. doi: 10.1097/MAO. 0b013e31818af3ad

Wangemann, P. (1997). [Potassium ion secretion and generation of the endocochlear potential in the stria vascularis]. HNO 45, 205-209. doi: 10.1007/ s001060050105

Wangemann, P. (2002). Cochlear blood flow regulation. Adv. Otorhinolaryngol. 59, 51-57. doi: 10.1159/000059241

Wangemann, P., Itza, E. M., Albrecht, B., Wu, T., Jabba, S. V., Maganti, R. J., et al. (2004). Loss of KCNJ10 protein expression abolishes endocochlear potential and causes deafness in Pendred syndrome mouse model. BMC Med. 2:30. doi: 10.1186/1741-7015-2-30

Wong, M. L., Young, J. S., Nilaver, G., Morton, J. I., and Trune, D. R. (1992). Cochlear IgG in the C3H/lpr autoimmune strain mouse. Hear. Res. 59, 93-100. doi: 10.1016/0378-5955(92)90106-w

World Health Organisation (2021). Deafness and Hearing Loss. Available online at:https://www.who.int/news-room/fact-sheets/detail/deafness-and-hearingloss.2021 (accessed May 1, 2021).

Wu, J., Han, W., Chen, X., Guo, W., Liu, K., Wang, R., et al. (2017). Matrix metalloproteinase- 2 and -9 contribute to functional integrity and noise-induced damage to the blood-labyrinth-barrier. Mol. Med. Rep. 16, 1731-1738. doi: 10.3892/mmr.2017.6784

Wu, X., Steigelman, K. A., Bonten, E., Hu, H., He, W., Ren, T., et al. (2010). Vacuolization and alterations of lysosomal membrane proteins in cochlear marginal cells contribute to hearing loss in neuraminidase 1-deficient mice. Biochim. Biophys. Acta 1802, 259-268. doi: 10.1016/j.bbadis.2009.10.008

Xiong, H., Chu, H., Zhou, X., Huang, X., Cui, Y., Zhou, L., et al. (2011). Simultaneously reduced NKCC1 and $\mathrm{Na}, \mathrm{K}$-ATPase expression in murine cochlear lateral wall contribute to conservation of endocochlear potential following a sensorineural hearing loss. Neurosci. Lett. 488, 204-209. doi: 10. 1016/j.neulet.2010.11.030
Xue, W., Tian, Y., Xiong, Y., Liu, F., Feng, Y., Chen, Z., et al. (2021). Transcriptomic analysis reveals an altered Hcy metabolism in the stria vascularis of the pendred syndrome mouse model. Neural Plast. 2021:5585394. doi: 10.1155/ 2021/5585394

Ye, X., Smallwood, P., and Nathans, J. (2011). Expression of the Norrie disease gene (Ndp) in developing and adult mouse eye, ear, and brain. Gene Expr. Patterns 11, 151-155. doi: 10.1016/j.gep.2010.10.007

Zhang, F., Dai, M., Neng, L., Zhang, J. H., Zhi, Z., Fridberger, A., et al. (2013). Perivascular macrophage-like melanocyte responsiveness to acoustic trauma-a salient feature of strial barrier associated hearing loss. FASEB J. 27, 3730-3740. doi: 10.1096/fj.13-232892

Zhang, J., Hou, Z., Wang, X., Jiang, H., Neng, L., Zhang, Y., et al. (2021). VEGFA165 gene therapy ameliorates blood-labyrinth barrier breakdown and hearing loss. JCI Insight 6:e143285. doi: 10.1172/jci.insight.143285

Zhang, N., Cai, J., Xu, L., Wang, H., and Liu, W. (2020). Cisplatin-induced stria vascularis damage is associated with inflammation and fibrosis. Neural Plast. 2020:8851525. doi: 10.1155/2020/8851525

Zhou, Y., Song, J., Wang, Y. P., Zhang, A. M., Tan, C. Y., Liu, Y. H., et al. (2019). Age-associated variation in the expression and function of TMEM16A calciumactivated chloride channels in the cochlear stria vascularis of guinea pigs. Mol. Med. Rep. 20, 1593-1604. doi: 10.3892/mmr.2019.10423

Conflict of Interest: The authors declare that the research was conducted in the absence of any commercial or financial relationships that could be construed as a potential conflict of interest.

Publisher's Note: All claims expressed in this article are solely those of the authors and do not necessarily represent those of their affiliated organizations, or those of the publisher, the editors and the reviewers. Any product that may be evaluated in this article, or claim that may be made by its manufacturer, is not guaranteed or endorsed by the publisher.

Copyright (C) 2021 Yu, Zong, Du, Zhou, Li, Wang and Xiao. This is an open-access article distributed under the terms of the Creative Commons Attribution License (CC BY). The use, distribution or reproduction in other forums is permitted, provided the original author(s) and the copyright owner(s) are credited and that the original publication in this journal is cited, in accordance with accepted academic practice. No use, distribution or reproduction is permitted which does not comply with these terms. 